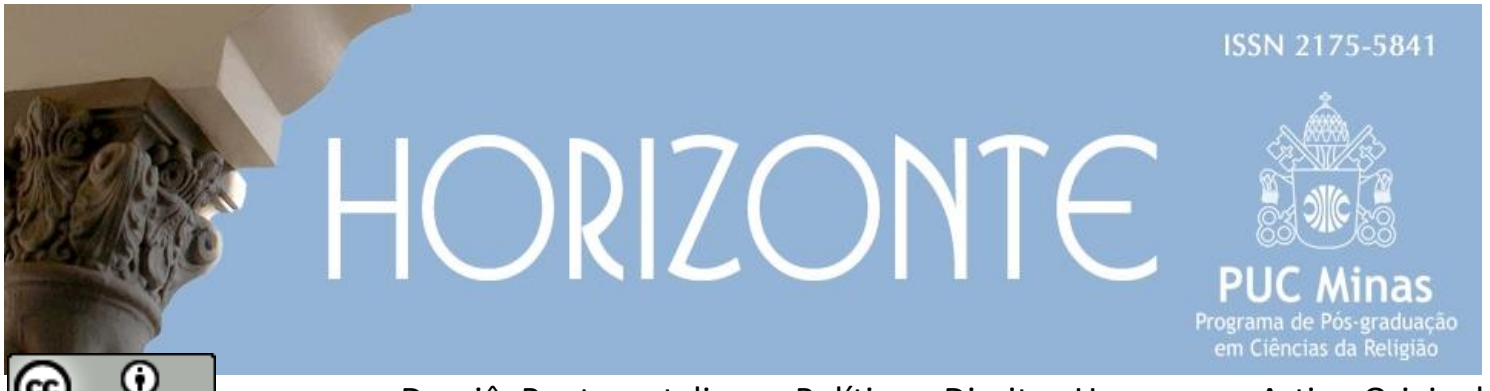

\title{
Manoel de Mello e a preocupação com Direitos Humanos nos primórdios do envolvimento pentecostal com a política brasileira
}

\author{
Manoel de Mello and the concern about Human Rights in the \\ beginnings of Pentecostal involvement in Brazilian politics
}

Carlos Ribeiro Caldas Filho*

\begin{abstract}
Resumo
Durante décadas os evangélicos pentecostais brasileiros evitavam a todo custo se envolver com política, pois esta considerada como algo sujo e indigno dos cristãos. Todavia, já há alguns anos é grande o envolvimento de líderes pentecostais em política. Muitos candidatos a cargos públicos apresentam-se como "Pastor Fulano", como uma maneira de chamar a atenção de eleitores evangélicos. Um dos primeiros líderes pentecostais brasileiros a falar abertamente sobre política foi Manoel de Mello e Silva (1929-1990), conhecido como Manoel de Mello, fundador da Igreja Evangélica Pentecostal O Brasil para Cristo (BpC). Este artigo pretende apresentar criticamente o contexto histórico da organização da Igreja O Brasil para Cristo e o envolvimento político de Manoel de Mello, com ênfase em sua preocupação com os Direitos Humanos, considerando ser ainda escassa a pesquisa acadêmica sobre o modelo de pentecostalismo no Brasil do qual a $\mathrm{BpC}$ é representante, e menor ainda o estudo desta vertente pentecostal na perspectiva de seu discurso político.
\end{abstract}

Palavras-chave: Pentecostalismo brasileiro. Manoel de Mello. Igreja Evangélica Pentecostal O Brasil para Cristo. Religião e política. Direitos Humanos.

\begin{abstract}
During decades Brazilian Pentecostal Evangelicals avoided at any cost to involve in politics, as it was considered dirty and unworthy of Christians. However, for some years now, it is great the involvment of Pentecostal leaders in politics. Many candidates to public positions present themselves as "Pastor So and So" as a way to call the attention of Evangelical voters. One of the first Brazilian Pentecostal leaders to speak openly about politics was Manoel de Mello e Silva (1929-1990), known as Manoel de Mello, who was founder of the Evangelical Pentecostal Church O Brasil para Cristo - Brazil for Christ (BfC). This article intends to present critically the historical context of the organization of $\mathrm{BfC}$ and the political involvement of Manoel de Mello, with emphasis on his concerning regarding Human Rights, considering it is still rare the academical research on the model of Pentecostalism in Brazil of which BfC is representative, and it is even lesser the research of this Pentecostal branch in the perspective of its political speech.
\end{abstract}

Keywords: Brazilian Pentecostalism. Manoel de Mello. Brazil for Christ Evangelical Pentecostal Church. Religion and Politics. Human Rights.

Artigo submetido em 3 de março de 2021 e aprovado em 8 de maio de 2021.

\footnotetext{
* Doutor em Ciências da Religião pela Universidade Metodista de São Paulo. Professor da PUC Minas. País de origem: Brasil. E-mail: crcaldas2009@hotmail.com
} 


\section{Introdução}

Por primeiro, duas constatações: uma, a que é fato sobejamente conhecido que já há alguns anos é grande o número de evangélicos pentecostais ocupando cargos políticos no Brasil, em nível municipal, como vereadores em um sem número de cidades em praticamente todos os estados da Federação, e em nível estadual e federal, como deputados (cf. LACERDA, 2017; DANTAS, 2019, p. 51-98). É conhecida, tanto do público leigo em ciência política como também de analistas do cenário político brasileiro a expressão "Bancada da Bíblia"1, usada para se referir à articulação de deputados federais em sua maioria provenientes de igrejas pentecostais em torno de pautas ultraconservadoras, como a diminuição da maioridade penal, a revogação do Estatuto da Família e a resistência e rejeição à descriminalização do aborto enquanto política de saúde pública. Outra característica da atuação deste grupo de políticos é sua luta a favor de causas de interesse próprio, como isenção fiscal para suas igrejas. A "Bancada da Bíblia” teve papel de protagonismo durante o processo de impedimento da então Presidente Dilma Rousseff e tem hipotecado apoio amplo, geral e irrestrito ao atual Presidente Jair Bolsonaro. Figuras conhecidas no cenário brasileiro, como o Deputado Federal Marco Feliciano, da Assembleia de Deus, e o pastor Silas Malafaia, também assembleiano, são exemplos desse modelo de envolvimento pentecostal brasileiro com a política. Dantas resume de maneira precisa a atuação da bancada evangélica (a "Bancada da Bíblia” acima citada, conquanto formada majoritariamente por evangélicos tem também apoio tácito de parlamentares de confissão católica romana, ligados ao movimento teologicamente conservador da RCC, a Renovação Carismática Católica) no Congresso nos últimos anos. Conforme a pesquisadora, a grande preocupação desses parlamentares tem sido promover "mecanismos de naturalização da realidade, universalização de leis particulares, justificação da ordem estabelecida e legitimação do poder dominante. ” (DANTAS, 2011, p. $321)^{2}$. A mesma pesquisadora aponta o crescimento e fortalecimento dos evangélicos na política partidária brasileira depois das eleições de 2014:

\footnotetext{
${ }^{1}$ A expressão "Bancada da Bíblia" foi criada pela Deputada Erika Kokay (PT-DF) em 2014, após as eleições gerais daquele ano, para se referir aos parlamentares eleitos ligados aos movimentos armamentista (a "bancada da bala"), ruralista (a "bancada do boi") e aos evangélicos (a citada "bancada da Bíblia").

${ }^{2}$ A referência é extraída da tese de doutoramento em Psicologia Social defendida na PUC de São Paulo por Bruna Suruagy do Amaral Dantas em 2011. A tese foi publicada com o mesmo título em forma de livro em 2019. O presente artigo se valeu dos dois trabalhos.
} 
Além de eleger 78 parlamentares (75 deputados federais e 3 senadores), conquistou a presidência da Câmara Federal, ocupada pelo deputado evangélico Eduardo Cunha (PMDB - RJ). No entanto, ainda busca mais espaço institucional em Brasília, a fim de ampliar seu poder de influência, barganha e interferência nas decisões nacionais. A bancada é maior que muitas legendas partidárias, e outras bancadas legislativas, como a sindical e a feminina, na ocasião compostas respectivamente por 46 e 45 parlamentares. (DANTAS, 2019, p. 16-17).

Esta constatação é, no mínimo, curiosa, se for levado em conta que durante décadas os evangélicos brasileiros, notadamente os pentecostais, não viam com bons olhos seu envolvimento com política, entendida como sendo algo impuro, impróprio para os cristãos. Mas, salvo algumas (poucas) exceções, muitos evangélicos, tanto protestantes tradicionais "históricos" ou "clássicos" como também pentecostais têm se lançado na política partidária na luta por um projeto de poder, em torno de uma microética, isto é, uma ética pessoal que tem como eixo questões de natureza sexual, que para a maioria absoluta dos evangélicos brasileiros, são mais importantes que outras, como a denúncia da injustiça em qualquer forma que esta possa assumir, a luta contra a desigualdade social e a defesa dos direitos humanos (doravante, DH) e do meio ambiente3, temas que na literatura bíblica ocupam muito mais espaço que os ligados à ética sexual. Fato é que até a metade do século passado os evangélicos em geral evitavam envolvimento com a política partidária. Isso não quer dizer um apoliticismo geral, total, completo e absoluto por parte dos evangélicos. $\mathrm{O}$ que se pretende afirmar é que percebe-se na história dos evangélicos na sociedade brasileira um crescendo no que diz respeito ao envolvimento com a política. De fato, percebe-se não apenas um envolvimento "simples", por assim dizer, mas mais que isso, busca de um projeto de poder. Quanto a isso, Ariovaldo Ramos, conhecido pastor evangélico brasileiro, relata um fato do qual foi testemunha ocular:

Com outros pastores e pregadores da Palavra de Deus, fui convidado a falar em uma grande igreja. Pregamos pela manhã e, na hora do almoço, fomos recebidos no refeitório pastoral, para almoçarmos juntos. Para minha surpresa, o líder daquela denominação, junto com todos nós, e na frente de todos, começou a delimitar quantos votos cada pastor ali presente deveria angariar para uma candidata a vereadora que também estava no almoço, com o esposo - que era deputado estadual -, para que fosse eleita em nome da Igreja. Sem

3 Para detalhes quanto ao peso da microética de evangélicos brasileiros consultar CALDAS (2019 a). 
nenhum pudor, o líder da Igreja se dirigia aos pastores de sua denominação, de acordo com o tamanho da igreja, estabelecendo o número de votos que deveriam conquistar para haver êxito na eleição daquela senhora. Assisti àquela situação com certo estarrecimento. Mas, aos poucos, fui me dando conta de que estava olhando para uma nova realidade: a Igreja evangélica começava a pensar como um dos elementos constitutivos do poder. Naquele almoço percebi que as eleições deixavam de ser um embate entre cidadãos para se tornarem um confronto entre instituições de toda ordem, e a Igreja estava se colocando como uma dessas instituições, em luta pelo controle do poder. Em outra cena, em reunião promovida por uma autodenominada rede de apóstolos, uma nova casta da liderança evangélica surgida no bojo de uma das variantes mais místicas da fé pentecostal e neopentecostal trava a batalha espiritual que acredita que o maligno se incrusta em instituições e que destas deve ser desalojado; e que isso se faz por meio da mística e da tomada consciente do poder político. Ouvi um deputado federal alegar que a defesa do direito da Igreja ao poder era a máxima de seu mandato. (RAMOS; ZACARIAS, 2017).

A cena relatada por Ariovaldo Ramos certamente tem se repetido à farta em todo o país nos últimos anos: evangélicos se envolvem cada vez mais com política, mas na maior parte das vezes visando apenas interesses particulares, e não em busca do que é do interesse da sociedade como um todo4.

A segunda constatação inicial é a abundância de pesquisas e trabalhos na academia brasileira de estudos - ciência(s) - da religião pesquisas sobre o primeiro pentecostalismo do Brasil, representado pela Igreja Evangélica Assembleia de Deus e pela Congregação Cristã do Brasil, e, de igual maneira, sobre o assim chamado neopentecostalismo, representado por igrejas como a Internacional da Graça de Deus, de R. R. Soares, Mundial do Poder de Deus, de Valdemiro Santiago, Plenitude do Trono de Deus, de Agenor Duque, e a maior e mais midiaticamente visível de todas, a Universal do Reino de Deus, de Edir Macedo. Todavia, são ainda poucas as pesquisas sobre o pentecostalismo que, cronologicamente falando, está entre o primeiro e o (por enquanto) terceiro modelo pentecostal do país. Nesta mesma linha, há que se lembrar que não há consenso entre os estudiosos do pentecostalismo brasileiro quanto à terminologia para se referir ao mencionado "pentecostalismo intermediário” no

\footnotetext{
4 Mas há que se ter em mente que não é possível fazer nenhuma generalização, pois nem todo político evangélico atua apenas na base do fisiologismo, troca de favores e em busca do interesse apenas da igreja que o elegeu. Um exemplo é apresentado na pesquisa que resultou na tese de doutorado em Ciências Sociais defendida na UFMG por ALEIXO (2019) apresenta dados detalhados sobre atuação de parlamentares evangélicos em Minas Gerais e suas propostas de projetos de leis e atuação na defesa de pautas de interesse da sociedade como um todo, e não de interesse particular das igrejas das quais estes parlamentares são membros.
} 
país: o sociólogo anglo-brasileiro Paul Freston popularizou a teoria das ondas5, conforme a qual, o pentecostalismo de primeira onda, também conhecido como pentecostalismo clássico, conforme mencionado no parágrafo anterior, foi o primeiro a se instalar no país, no início do século passado, o de segunda onda foi o pentecostalismo surgido na metade do século passado, tanto por iniciativa missionária de origem estadunidense, como é o caso da Igreja do Evangelho Quadrangular, como de igrejas genuinamente nacionais, como é o caso da Igreja Pentecostal Deus é Amor e a BpC fundada por Manoel de Mello, que se constitui no objeto propriamente do presente artigo. O pentecostalismo de terceira onda por sua vez seria o modelo popularmente conhecido como neopentecostalismo. Todavia, alguns preferem falar em deuteropentecostalismo, isto é, um segundo (dêutero) pentecostalismo, não em termos de qualidade, mas em termos cronológicos. A rigor, não há diferença conceitual significativa entre pentecostalismo de segunda onda e deuteropentecostalismo. Por essa causa, o presente artigo utilizará a metáfora marinha trazida para o Brasil por Freston.

A partir destas duas observações iniciais surgem as perguntas que o presente artigo pretende responder: quando os pentecostais brasileiros começaram a se envolver com política? E qual era a ênfase deste envolvimento? Em busca de resposta para tais perguntas o artigo quer analisar, posto que em síntese, o envolvimento e o discurso de um dos primeiros (quiçá o primeiro) líder pentecostal brasileiro com política: o pernambucano Manoel de Mello e Silva (1929-1990), conhecido como Manoel de Mello, fundador da Igreja Evangélica Pentecostal O Brasil para Cristo (doravante, $\mathrm{BpC}$ ). Manoel de Mello, conforme se verá, teve um discurso político arrojado e ousado, no qual demonstrou sensibilidade para com as vítimas do governo militar no Brasil, ao qual não poupou críticas. E, conforme já apresentado, mesmo que apenas en passant, são poucos os estudos sobre o pentecostalismo de segunda onda e a BpC em geral, e sobre a atuação de Mello em particular, especialmente a partir do viés da análise do conteúdo da atuação política ${ }^{6}$. Afinal, Manoel de Mello em suas críticas ao governo de exceção que se estabeleceu no Brasil a partir do

\footnotetext{
5 Conforme Mariano (1999, p. 28) Freston adaptou para o contexto brasileiro a metáfora marinha que foi usada primeiramente pelo sociólogo britânico da religião David Martin, que falou de três grandes ondas do protestantismo: a puritana, a metodista e a pentecostal.

${ }^{6}$ Uma das poucas pesquisas que se conseguiu localizar sobre Mello e a BpC é a dissertação de mestrado em Ciências da Religião de LIMA (2008), que tem como objeto propriamente o uso do rádio como meio de comunicação por Mello.
} 
golpe militar de 1964 demonstrou preocupação com o tema dos DH, antecipando de certa forma o que se encontraria em discursos de líderes religiosos como o pastor presbiteriano Jaime Wright, o então arcebispo de São Paulo, Dom Paulo Evaristo Arns e o rabino Henry Sobel, da Congregação Israelita Paulista, notórios críticos do governo de exceção instaurado no Brasil7. Antes de prosseguir, uma ressalva importante precisa ser feita: a dificuldade em encontrar fontes primárias para uma análise crítica do discurso político de Mello, considerando que não há nenhuma coletânea de seus sermões. O que há é uma história oficial da denominação $\mathrm{BpC}$ publicada pela editora denominacional, escrita por um pastor membro da igreja (SUANA, 2015). Obras como estas servem mais como fontes de pesquisa, por apresentarem informações históricas que dificilmente poderiam ser obtidas por alguém não membro do $\mathrm{BpC}$, mas não exatamente como referência, porque biografias do líder fundador e histórias denominacionais produzidas muitas vezes literalmente por encomenda da diretoria da organização eclesiástica têm a tendência de, consciente ou inconscientemente, apresentar um relato laudatório, encomiástico, que exalta um mito de origem, sendo por conseguinte carentes de análise crítica propriamente.

Isto posto, pode-se prosseguir.

\section{Manoel de Mello e o contexto histórico da fundação da BpC}

Para uma síntese biográfica de Manoel de Mello seguir-se-ão as anotações da pesquisa de Freston (1996, p.116-125), que apresenta em sua "breve história do pentecostalismo brasileiro" a primeira pesquisa que se tem notícia a tratar da $\mathrm{BpC}^{8}$, o que é, no mínimo, curioso, considerando ter sido a $\mathrm{BpC}$ a primeira igreja pentecostal genuinamente brasileira, a primeira a eleger alguns de seus membros para cargos públicos e a primeira a se envolver oficialmente com o movimento ecumênico (FRESTON, 1996, p. 117). A respeito desta última afirmação, há que se registrar que, de fato, Mello foi um

\footnotetext{
${ }_{7}$ Quanto a isso, há que se lembrar que Dom Paulo Evaristo Arns e o Reverendo Jaime Wright foram responsáveis pela publicação da obra Brasil: Nunca Mais (ARNS, WRIGHT, 2014), com apoio do Conselho Mundial de Igrejas, um relatório abrangente e exaustivo de abusos contra os DH de 1964-1985, como torturas e desaparecimentos de presos políticos praticados pelo governo militar do Brasil contra dissidentes e críticos do regime.

8 O texto de Freston na obra organizada por Alberto Antoniazzi apresenta um histórico com considerável riqueza de informações sobre as principais igrejas e líderes das três ondas pentecostais no Brasil.
} 
pentecostal sui generis, por ter sido o primeiro e único (por enquanto) líder pentecostal brasileiro a tornar sua denominação integrante do CMI, o Conselho Mundial de Igrejas, organização ecumênica eclesiologicamente e progressista ou liberal - teologicamente, ou seja, duas características que para evangélicos conservadores, ou mesmo fundamentalistas, constituem-se em pecados imperdoáveis 9 . Nesta mesma linha, há que se lembrar que Mello, de maneira inegavelmente ousada, tornou a BpC integrante da CESE - Coordenadoria Ecumênica de Serviço, entidade formada por denominações ligadas ao CMI, que visava coordenar trabalhos de ação social em relação aos mais pobres e desfavorecidos (SILVA, 2011). Eis aí uma atitude que não se esperaria encontrar em um pastor pentecostal. Depois da morte de Mello sua denominação abandonou o CMI. Mas o fato que até hoje é a única denominação pentecostal brasileira a ter feito parte da maior entidade ecumênica do planeta é fato que não pode ser ignorado.

Conforme Freston (1996, p. 117) Manoel de Mello era pernambucano de nascimento, o sexto de nove filhos de uma família de lavradores. Seu pai era católico nominal e a mãe era membro da Assembleia de Deus. Portanto, desde sempre teve contato com uma cultura pentecostal, por assim dizer. Assim como milhares e milhares de outros nordestinos, moço ainda migrou para a capital de São Paulo em busca de melhores condições de vida, e conseguiu emprego na construção civil. Nesta época, ainda ligado à Assembleia de Deus, chegou a ser diácono ${ }^{10}$. Nesta ocasião, na primeira metade da década de 1950, aconteceu a chegada no Brasil da Igreja do Evangelho Quadrangular no Brasil, trazida por missionários provenientes dos Estados Unidos, que inovaram a estratégia de evangelização pentecostal ao realizar cultos não em templos, como até então os assembleianos faziam, mas em tendas, o que chamou a atenção do jovem pernambucano. Manoel de Mello passará um tempo com os quadrangulares, mas logo sairá para seguir "carreira solo", no final de 1955 ou início de 1956 (FRESTON, 1996, p. 118) dando origem ao seu próprio movimento. Não há como não notar o nome dado por Mello à sua novel denominação: O Brasil para Cristo. Manoel de Mello demonstrou ter grande sensibilidade para perceber o

\footnotetext{
9 Para detalhes sobre a relação entre o pentecostalismo brasileiro e o movimento ecumênico consultar ALENCAR (2018).

${ }^{10}$ A Assembleia de Deus tem uma hierarquia de ministérios, na qual o diaconato ocupa posição intermediária entre colaborador (a posição mais baixa) e pastor presidente (a mais elevada).
} 
Zeitgeist da sociedade brasileira de seus dias ao escolher para o movimento que viria a liderar um nome totalmente diferente de tudo que até então existia. Mello captou bem o clima de euforia, patriotismo e nacionalismo do Brasil daqueles dias: Juscelino Kubitschek fora eleito Presidente da República, e seu lema/slogan de campanha "50 anos em 5" empolgou o país. O anúncio da construção de uma cidade na região do planalto central para substituir o Rio de Janeiro na condição de capital federal funcionou como combustível na fogueira do entusiasmo patriótico do povo brasileiro. Afinal, tratava-se de projeto grandioso, que geraria milhares de empregos, ajudando a mover a economia, ou seja, algo perfeito para um projeto político nacional-desenvolvimentista como o implementado por Kubitschek. O nome escolhido para a nova capital - Brasília - remetendo ao nome do país, ajudou a fortalecer o sentimento patriótico. Nesse sentido, uma igreja evangélica com o nome do país em seu próprio nome foi uma decisão acertada de marketing. Conforme Freston

O sentimento de dignidade nacional e rechaço à dominação estrangeira se popularizavam, e a BPC representava o equivalente pentecostal desse sentimento. A visão era de uma igreja genuinamente brasileira, no sentido de independência econômica, liderança nacional, metodologia adaptada e o sonho de "ganhar a nação". (FRESTON, 1996, p. 118).

Mello mostrou ser um visionário: em 1958, quando o Brasil ganhou a Copa do Mundo de Futebol pela primeira vez, na Suécia, o pregador pentecostal pernambucano lotava o Estádio do Pacaembu em feriados nacionais com cultos com a presença de autoridades civis e militares e bandas do Exército (FRESTON, 1996, p. 118-119). Passos apresenta uma síntese do que foi a BpC sob a égide de Manoel de Mello:

A Igreja Evangélica Pentecostal o Brasil para Cristo marcou importante capítulo na história do pentecostalismo brasileiro. Sua aparição no universo religioso pentecostal estabeleceu as bases para a sublimação do deuteropentecostalismo. O perfil empreendedor do seu líder espiritual ladrilha a caminho das novas denominações pentecostais. Suas estratégias litúrgicas, organizacionais e de marketing religioso configuraram o preâmbulo de um novo paradigma pentecostal em gestação no Brasil. Manoel de Mello morreu em 1990. Sua igreja perdeu a imponência de outrora, mas seu legado suscitou o surgimento de novos impérios religiosos nacionais e transnacionais dotados de uma estrutura e poder político, algo imaginável em seu tempo. (PASSOS, 2014, p. 195). 
Samuel Suana menciona, sem citar fontes comprobatórias, datas ou quaisquer detalhes, que Mello, a quem apresenta como "um dos maiores pregadores que esse país já conheceu”, foi preso mais de vinte vezes, pregou em mais de cem países, testemunhou para a rainha da Inglaterra, o presidente dos Estados Unidos, o primeiro-ministro da Alemanha e falou nos maiores auditórios e estádios de futebol do Brasil (SUANA, 2015, p. 22). O fato de Suana citar acontecimentos grandiosos da vida de Mello sem, todavia, apresentar qualquer fonte sugere que deve ter havido uma tradição oral que criou um mito em torno da figura do líder, que glorifica os feitos do fundador.

Resumindo: Mello foi um líder arrojado, que percebeu com clareza os "sinais dos tempos", e conseguiu revitalizar o pentecostalismo (em termos de estratégia evangelística, mas não em termos doutrinários ou litúrgicos) através de sua atuação na BpC.

\section{Manoel de Mello e seu envolvimento político}

Outro aspecto no qual Mello foi pioneiro é quanto ao envolvimento na política partidária. No início dos anos de 1960 Levy Tavares foi eleito deputado federal por São Paulo, e Geraldino dos Santos, deputado estadual, sendo ambos pastores da igreja BpC (CAMPOS, 2006, p. 44). O que hoje é comum, isto é, um pastor pentecostal sendo eleito para um cargo público, teve início há quase seis décadas com a atuação de Manoel de Mello, que fez com que alguns de seus liderados fossem eleitos. O próprio Mello nunca se candidatou, mas em seu discurso religioso era frequente a menção a temas políticos, notadamente, críticas ao governo militar, o que o diferenciava dos demais pregadores pentecostais. Quanto a isso, Freston afirma:

Nos anos 60 Manoel de Mello ficou conhecido como um líder pentecostal que criticava o governo militar, lutava pela justiça social e tinha uma visão ecumênica do cristianismo. Quanto disso é verdade? A liderança atual afirma que os pronunciamentos que Mello fazia eram pessoais e não refletiam a opinião da igreja, na época pouco estruturada. A lembrança desses fatos é incômoda para a igreja atual. Quanto às raízes de seu progressismo político, parece ter sido uma mistura de preocupação genuína e estratégia. Sua experiência como trabalhador na construção civil talvez tenha ajudado a dar-lhe uma percepção mais estrutural da sociedade do que a de outros líderes 
pentecostais ${ }^{11}$. Aceitou participar da fundação da CESE (Coordenadoria Ecumênica de Serviço), em reuniões quase clandestinas durante o governo Médici. Por outro lado, suas afirmações mais contundentes foram direcionadas a públicos externos à BPC. Sem negar a natureza genuína de suas preocupações sociais, ele tinha uma percepção clara do custo-benefício em ambientes diversos: na BPC, o custo em termos de rejeição ou medo por partes dos membros poderia prevalecer; nos meios ecumênicos, o benefício em termos de prestígio e verbas para projetos compensava o risco. (FRESTON, 1996, p. 123-124).

Mello então protagonizou o pioneirismo na inserção pentecostal na política partidária brasileira. Mas há outro aspecto do envolvimento político de Mello que precisa ser destacado, que foi sua crítica ao governo militar. O período do governo militar no Brasil - 1964-1985 - teve como uma de suas características a repressão violenta aos opositores e críticos do regime. Em 1979 o General João Baptista de Oliveira Figueiredo, então presidente do Brasil, decretou a Lei da Anistia, que visava dar início a um processo de abertura e redemocratização do país. Uma matéria publicada no jornal Expositor Cristão, órgão informativo oficial da Igreja Metodista no Brasil apresentou depoimentos de dois líderes religiosos, um católico e um pentecostal, que criticaram alguns aspectos jurídicos da mencionada lei e perguntaram a respeito do paradeiro dos "desaparecidos que foram presos em nome da segurança nacional” ${ }^{12}$. Uma fala desta natureza, arriscada naqueles dias, levantava a questão das vítimas do governo militar, tema tabu em um tempo em que era perigoso tocar neste tipo de assunto ${ }^{13}$. O líder católico era Dom Paulo Evaristo Arns, e o pentecostal, Manoel de Mello. Encontrar uma denúncia deste jaez em uma figura do calibre de Dom Paulo Evaristo Arns não é surpreendente, antes, é até mesmo esperado. Mas é surpreendente encontrar a mesma denúncia em um Manoel de Mello, homem com pouca instrução formal - Mello era alfabetizado, e só. Antes de prosseguir, uma ressalva importante: ao destacar que Mello não tinha graus elevados de instrução formal não se está de modo algum expressando qualquer visão preconceituosa ou depreciativa a respeito do fundador da BpC. Muito pelo

\footnotetext{
${ }^{11}$ A hipótese aventada por Freston que o fato de ter sido trabalhador na construção civil talvez tivesse conferido a Mello "uma percepção mais estrutural da sociedade" faz lembrar a poesia $O$ operário em construção, de Vinícius de Moraes, que é uma releitura do episódio bíblico da tentação de Jesus no deserto pelo diabo (Mt 4.1-11; Lc 4,1-13). Na poesia, o operário e seu patrão, ambos não nomeados, representam respectivamente os papeis de Jesus e do diabo. É curioso que a poesia, de maneira não teórica ou sistematizada, antes, sugestiva, apresenta uma síntese de elementos do cristianismo e do marxismo, antecipando assim em algumas décadas intuições da Teologia da Libertação latinoamericana.

${ }_{12}^{12}$ Católicos e pentecostais falam sobre a anistia. Expositor Cristão. Ano 94, N. 16. São Paulo, 15 de agosto de 1979, p. 11.

${ }^{13}$ A este respeito, é oportuno lembrar a advertência feita por Paul Ricoeur que as vítimas precisam contar suas histórias e nomear seus algozes, para não acontecer que violências do passado sejam repetidas (RICOEUR, 2006, p. 239-246).
} 
contrário, o que se pretende é destacar sua visão de longo alcance em relação a problemas sociais e ao tema dos DH. A propósito, vale registrar que conforme a biografia de Mello ele foi (ou teria sido) preso por 27 vezes (MELLO, 2006, p. 83). Lima comenta que não é possível saber o quanto dessa afirmação é verdade considerando que "não eram prisões com lavramento de inquérito, mas detenções para esclarecimento (LIMA, 2008, p. 77). O já citado Levi Tavares afirma que de fato Mello foi detido algumas vezes por criticar o governo militar e a repressão do regime de exceção em algumas de suas pregações. Amigo de Mello, Tavares usou sua influência enquanto deputado para impedir que o líder da BpC fosse autuado. Conforme Tavares certa feita um delegado do DOPS (Delegacia de Ordem Política e Social) lhe teria dito: "Tavares, segura seu chefe porque não posso ficar livrando a pele dele" (apud LIMA, 2008, p. 77).

Há um episódio mencionado na biografia de Mello que merece ser reproduzido: em 1975 em uma pregação em emissora de rádio Mello afirmou: "Só Deus tem o direito de tirar a vida de uma pessoa. O General não tem esse direito, nem o médico tem esse direito sobre a vida de um ser humano”. A frase custou a Mello uma detenção de 30 horas em uma delegacia da Polícia Federal, após as quais foi transferido para o temido DOPS, onde, mais uma vez, foi liberado por influência do Deputado Levy Tavares (MELLO, 2006, p. 152).

É no mínimo curioso saber a respeito de um pregador pentecostal que em um período tão difícil, quando o governo de exceção adotava slogans do tipo Brasil: ame-o ou deixe-o, era contundente em seus posicionamentos críticos e levantava sua voz a favor das vítimas do regime. Além disso, conforme observado por Freston, Mello demonstrou em suas pregações ter sensibilidade em relação a problemas sociais, algo não encontrado com muita frequência em outros pregadores pentecostais ${ }^{14}$. Em outras palavras: a pregação de Mello não era escapista ou alienante, pois falava de problemas concretos do dia a dia. Há que se destacar que este aspecto da sensibilidade em relação a problemas sociais apresentado na pregação de Mello não foi observado primeiramente por Freston. Alguns anos antes a socióloga Beatriz Muniz de Souza já observara:

\footnotetext{
${ }_{14}$ Não se pretende de modo algum afirmar que Mello foi o único pregador pentecostal brasileiro a demonstrar sensibilidade em relação a temas de natureza social. A questão é que muitas igrejas evangélicas brasileiras, pentecostais e não pentecostais tem tratado questões sociais em perspectiva assistencialista, revelando assim compreensão diferente do problema em relação a grupos protestantes progressistas, que pensam em termos de transformação social e emancipação do indivíduo.
} 
$\mathrm{O}$ traço nacionalista antes apontado adquire na igreja "O Brasil para Cristo" maior amplitude e significado. Na mensagem evangélica que prega, fica bem nítido, de modo não encontrado em nenhuma outra das congregações pentecostais abrangida em nossa coleta de dados, o interesse pelos problemas sociais brasileiros. (SOUZA, 1969, p. 42).

\section{Conclusão}

$\mathrm{Na}$ introdução do presente artigo foi feita referência ao envolvimento de pentecostais, independentemente de qual seja a classificação na qual estejam alocados, com a política nacional. É imperioso observar que a agenda dos políticos pentecostais se caracteriza pela defesa de uma ética do indivíduo, com ênfase em questões de moral sexual. O que se vê no presente é um adesismo acrítico de líderes políticos e eclesiásticos pentecostais ao atual governo federal, em que se faz "vista grossa" a contradições flagrantes desse governo em relação a princípios basilares do evangelho. Eis aí uma contradição: muitos líderes evangélicos veem na figura do atual Presidente da República uma espécie de defensor da fé e de valores cristãos, esquecendo-se do "princípio protestante" exposto por Paul Tillich - para o teólogo alemão, o princípio protestante é o princípio profético por excelência, de uma desconfiança a priori de todo e qualquer poder ou instituição (CALDAS, 2019 b). Quando líderes evangélicos pentecostais e neopentecostais, e de igual maneira, líderes de igrejas protestantes "tradicionais" ou "históricas" atribuem uma virtual inerrância ao atual Presidente da República, não admitindo que crítica nenhuma lhe seja feita, acabam por se esquecer de mandamentos bíblicos como "Não confieis em príncipes nem nos filhos dos homens, em quem não há salvação” (Sl 146, 3). A ausência de espírito profétic ${ }^{15}$ da maioria absoluta dos atuais líderes eclesiásticos e políticos brasileiros faz surgir uma versão tupiniquim do Positives Christentum, o "Cristianismo Positivo" na Alemanha na época da Segunda Guerra Mundial, quando cristãos (na sua maioria protestantes, mas também católicos) viam em Adolf Hitler um defensor da fé cristã que não poderia ser criticado (CALDAS, 2020).

\footnotetext{
${ }^{15}$ A expressão "espírito profético" se refere à ação de líderes religiosos que emulam o profetismo hebreu clássico do oitavo século antes da era cristã, no sentido de fazer crítica aos poderes instituídos. Este profetismo tem em figuras como Isaías, Amós e Miqueias seus representantes mais conhecidos.
} 
Toda esta situação apresenta contraste nítido com os primórdios do envolvimento pentecostal com a política no Brasil, com Manoel de Mello e a BpC. Mello, pelos motivos apresentados, foi um líder pentecostal diferente dos demais. Foi ousado em muitas de suas pregações em emissoras de rádio, quando criticou o governo militar e fez ouvir sua voz a favor das vítimas do regime, apresentando assim, ainda que de maneira não muito exuberante, uma sensibilidade em relação ao tema dos $\mathrm{DH}$. Todavia, há que se observar que os líderes da $\mathrm{BpC}$ depois da morte de Mello não seguiram sua linha de críticas ao governo e de levantar a voz em nome dos perseguidos por este governo. A BpC continua em ação no Brasil, mas é uma sombra do que já foi.

A trajetória de Mello leva a conjecturar o que teria (ou o que poderia ter) acontecido se a BpC tivesse seguido a linha de seu fundador e continuasse com um modelo de ação tipicamente pentecostal, conservador teologicamente, carismático liturgicamente, mas engajado socialmente e ecumênico eclesiologicamente. Quanto a isso, só se pode especular. A ousadia de Mello espantou a liderança da BpC depois de sua morte, o que fez com que a denominação se retirasse dos movimentos ecumênicos, tanto em nível nacional - no caso, a citada CESE - como em nível mundial - no caso, o CMI. Não há nenhum registro documental a respeito, mas é razoável admitir que a cúpula denominacional da $\mathrm{BpC}$ deve ter orientado seus pregadores a que deixassem de lado o envolvimento político e que concentrassem suas pregações apenas em temas “espirituais", abandonando por completo qualquer crítica ao governo.

Nos anos que se seguiram os pentecostais brasileiros foram pouco a pouco deixando de lado seus pruridos e suas reservas em relação ao envolvimento político. E quando o fizeram, quase todos caíram no extremo oposto em relação ao de Manoel de Mello e a BpC, pois adotaram uma atitude de deixar completamente de lado a postura de testemunho profético de independência e crítica em relação aos poderes constituídos. Nesse sentido, Manoel de Mello, décadas depois de sua morte, continua a ser uma alternativa, pois é um caso praticamente único na história do envolvimento pentecostal com a política brasileira. 


\section{REFERÊNCIAS}

ALEIXO, Vitor Corrêa. Religião e política em Minas Gerais: formas de ativismo cristão no poder legislativo e em controvérsias públicas. 2019. Tese (Doutorado em Sociologia) - Universidade Federal de Minas Gerais, Belo Horizonte, 2019.

ALENCAR, Gedeon Freire de. Ecumenismos \& Pentecostalismos: a relação entre o pescoço e a guilhotina? São Paulo: Recriar, 2018.

ALMEIDA, Adroaldo José Silva. Pelo Senhor, marchamos: a ditadura militar e os evangélicos no Brasil (1964-1985). 2019. Tese (Doutorado em História) - Universidade Federal Fluminense, Niterói, 2019.

ARNS, Paulo Evaristo; WRIGHT, Jaime (org.). Brasil: nunca mais. 41. ed. Petrópolis: Vozes, 2014.

CALDAS, Carlos. "Não posso suportar iniquidade associada ao ajuntamento solene". O "Cristianismo Positivo" tupiniquim. 2020. IHU Online. Disponível em:

http://www.ihu.unisinos.br/78-noticias/598306-nao-posso-suportar-iniqueidadeassociada-ao-ajuntamento-solene-o-cristianismo-positivo-tupiniquim. Acesso em: 23 fev. 2021.

CALDAS, Carlos. Evangélicos sem o princípio protestante. 2019b. IHU Online. Disponível em: http://www.ihu.unisinos.br/78-noticias/592535-evangelicos-sem-oprincipio-protestante. Acesso em: 23 fev. 2021.

CALDAS, Carlos. Microética evangélica e frases de efeito: ingredientes para adesão ao governo Bolsonaro. Entrevista especial com Carlos Caldas. 2019a. IHU Online. Disponível em: http://www.ihu.unisinos.br/159-noticias/entrevistas/593336microetica-evangelica-e-gestos-de-efeito-ingredientes-para-adesao-ao-governobolsonaro-entrevista-especial-com-carlos-caldas. Acesso em: 23 fev. 2021.

CAMPOS, Leonildo Silveira. Os políticos de Cristo - uma análise do comportamento político de protestantes históricos e pentecostais no Brasil. In: BURITY, Joanildo A.; MACHADO, Maria das Dores C. (org.). Os votos de Deus: evangélicos, política e eleições no Brasil. Recife: Fundação Joaquim Nabuco, 2006. p. 29-90.

DANTAS, Bruna Suruagy do Amaral. Religião e política: ideologia e ação da "Bancada Evangélica" na Câmara Federal. 2011. Tese (Doutorado em Psicologia Social) - Pontifícia Universidade Católica de São Paulo, São Paulo, 2011.

DANTAS, Bruna Suruagy do Amaral. Religião e política: ideologia e ação da "Bancada Evangélica" na Câmara Federal. São Paulo: Annablume, 2019.

FRESTON, Paul. Breve história do pentecostalismo brasileiro. In: ANTONIAZZI, Alberto (org.). Nem anjos nem demônios: interpretações sociológicas do pentecostalismo. 2. ed. Petrópolis: Vozes, 1996.

LACERDA, Fábio. Pentecostalismo, eleições e representação política no Brasil contemporâneo. 2017. Tese (Doutorado em Ciência Política) - Universidade de São Paulo, São Paulo, 2017. 
Dossiê Pentecostalismo, Política e Direitos Humanos - Artigo Original: Manoel de Mello e a preocupação com Direitos Humanos nos primórdios do envolvimento pentecostal com a política brasileira

LIMA, José Hélio de. O programa “A Voz do Brasil para Cristo”: a relação estabelecida entre o líder pentecostal Manoel de Mello e o rádio. 2008. Dissertação (Mestrado em Ciências da Religião) - Universidade Presbiteriana Mackenzie, São Paulo, 2008

MARIANO, Ricardo. Neopentecostais: sociologia do novo pentecostalismo no Brasil. São Paulo: Loyola, 1999.

MELLO, Valéria Augusto. Missionário Manoel de Mello: vida e obra. Biografia autorizada. São Paulo: S/E, 2006.

PASSOS, Paulo Rogério Rodrigues. As premissas do deuteropentecostalismo: tradição e renovação no campo religioso brasileiro. Observatório da Religião, Pará, v. 1, n. 1, p. 188-198, 2014.

RAMOS, Ariovaldo; ZACARIAS, Nilza Valéria. Neopentecostais e o projeto de poder. Le Monde Diplomatique, 20 de março de 2017. Disponível em: https://diplomatique.org.br/neopentecostais-e-o-projeto-de-poder/. Acesso em: 14/02/2021.

RICOEUR, Paul. A memória do sofrimento. In: RICOEUR, Paul. A hermenêutica bíblica. São Paulo: Loyola, 2006.

SILVA, Elizete da. O Conselho Mundial de Igrejas e a trajetória do ecumenismo no Brasil. Anais do XII Simpósio Anual da ABHR. Juiz de Fora, 2011.

SOUZA, Beatriz Muniz de. A experiência da salvação: pentecostais em São Paulo. São Paulo: Duas Cidades, 1969.

SUANA, Samuel. Uma história da Igreja O Brasil Para Cristo. São Paulo: Editora OPBC, 2015. 